\title{
PROSPECTS OF RARE EARTH ELEMENTS TO CREATE A NEW GENERATION OPTICAL AMPLIFIERS
}

Sultonova Makhbuba Odilovna Tashkent University of Information Technologies Named after Muhammad al-Khwarizmi, assistant E-mail: $\underline{\text { maxbubB@yandex.ru }}$ ORCID ID: 0000-0003-4818-629X

\section{Crossref $_{\underline{h t t p: / / d x . d o i . o r g / 10.26739 / 2433-202 x ~}}$}

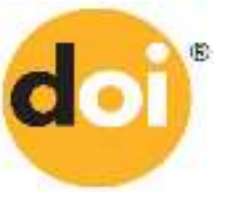

Issue DOI http:/ / dx.doi.org/10.26739/2433-202x-2017-6-6

Article DOI http://dx.doi.org/10.26739/2433-202x-2017-6-6-9

The article analyzes the possibilities of using production rare earth elements to create optical amplifiers are the main issues that need to be addressed in the further development of optical fiber amplifiers based on optical fibers doped with rare earth elements. The methods of doping ion optical materials used in optical fiber amplifiers, ion implantation process steps, estimation of the depth of penetration of the ions of rare earth elements in the surface layers of optical materials, it is shown that a method for plasma ion implantation of dopants of rare earth elements is one of the most promising and efficient methods.

Key Words: Fiber-optic transmission systems (FOTS), the types of optical amplifiers (TOA), rare earth elements (REE), optical fiber (F) of fiberoptic communication lines (fiber optic), doping optical materials (DOM), erbium (Er), neodymium $(\mathrm{Nd})$, terbium $(\mathrm{Tb})$, ytterbium, optical radiation 
(OR), the optical signal (OS), a fiber optic backbone, depth concentration, ionplasma implantation.

\section{ПЕРСПЕКТИВЫ ИСПОЛЬЗОВАНИЯ РЕДКОЗЕМЕЛЬНЫХ ЭЛЕМЕНТОВ ДЛЯ СОЗДАНИЯ ОПТИЧЕСКИХ УСИЛИТЕЛЕЙ НОВОГО ПОКОЛЕНИЯ}

\section{Султонова Махбуба Одиловна}

Ташкентский университет информационных технологий имени Мухаммада ал-Хоразмий, ассистент

В статье производттся анализ возможностей использования редкоземельных элементов для создания оптических усилителей, приводятся основные проблемы, которые необходимо решить при дальнейших разработках волоконно-оптических усилителей на основе оптических волокон, легированных редкоземельными элементами. Рассматриваются методы ионного легирования оптических материалов, используемых в волоконно-оптических усилителях, этапы процесса ионного легирования, оценка глубины проникновения ионов редкоземельных элементов в приповерхностные слои оптических материалов, показано, что метод ионно-плазменной имплантации легирующих примесей редкоземельных элементов является одним из перспективных и эффективных методов.

Ключевые слова: Волоконно-оптические системы передачи (ВОСП), виды оптических усилителей (ВОУ), редкоземельными элементами (РЗЭ), оптоволокно (ОВ), волоконно-оптические линии связи (ВОЛС), легирования оптических материалов (OM), эрбий (Er), неодим $(\mathrm{Nd})$, тербий $(\mathrm{Tb})$, иттербий, оптическое излучение (ОИ), оптический сигнал (ОС), магистральные оптоволоконные линии, глубина концентрации, ионно-плазменная имплантация. 
В настоящее время в волоконно-оптических системах передачи (ВОСП) идут интенсивные исследования и разработки новые видов оптических усилителей (ВОУ) на основе оптических волокон, легированные редкоземельными элементами (РЗЭ).

В 1961 году Супер [1] предложил идею использовать оптическое волокон с излучателем редкоземельных элементов (РЗЭ) для усиления световых волны. Позднее он уже создал первый лазер на стекле с присадкой эрбия (Er). Позднее эта технология стала перспективной для создания видов оптические усилителей и лазеров, световая мультиплексоров и изоляторов для быстро действующая фидерных устройств и особенно это идея оказалась весьма перспективной для изготовления оптического волокно $(\mathrm{OB})$, используемого в ВОЛС.

Сегодня проводятся обширные экспериментальные исследования в области легирования оптических материалов редкоземельными элементами (PЕМ) для обработки оптических материалов, используемые в ВОЛС (волоконно-оптические линии связи) и оптических усилителях. Уже имеются активные образцы оптических усилителей на основе эрбия (Er), позволяющие увеличивать длину передачи информации между усилителями и снизить потери оптических сигналов. Кроме эрбия весьма перспективными являются возможности использования и других редкоземельных элементов - неодима, диспрозия, самария. Создание технологии модифицированного оптического волокна РЕМ может решить проблему уменьшения потерь оптических сигналов для увеличение длины передачи информации и создания, протяженных линии оптической передачи спиральных характеристик ВОЛС и улучшить использование их скоростной передачи.

В таблице 1 проведены данные редкоземельных элементов с соответствующими характеристиками. Как видно из таблица 1 параду с Er перспективными элементами является Неодим $(\mathrm{Nd})$, тербий $(\mathrm{Tb})$ и иттербий (Yb). Рассмотрим характерный экспериментальный уровень $\mathrm{Er}$ на рисунке 2 характерная диаграмма энергетического уровня $\mathrm{Yb}^{3+}$. На рис.3 приведен характерный спектр энергетического уровня элементов эрбия и время диффузии. Рассмотрение трех низких уровней энергий Physical, Chemical Science and Engineering Sultonova Makhbuba Odilovna 
трехвалентного иона эрбия использовать - низкой уровне $\mathrm{E}_{1}$. является основными, верхние $\mathrm{E}_{3}$ - возбужденным, на который при накачке фотона забрасывает электрон из основного состояния. Второй $\mathrm{E}_{2}-$ промежуточный для него характерно очень больше время диффузии электронов эрбия $\tau_{\mathrm{r}}=10 \mathrm{M \kappa c}$, что на порядок и более превышает время диффузии на других уровнях. Уровень $\mathrm{E}_{2}$ можно считать метастабильным. За счет этого «релаксирующие» частицы, возвращающие с время уровней в результате безизлучательных переходов, накладывается на уровне $\mathrm{E}_{2}$ в большем количестве. Переход между уровнями $\mathrm{E}_{2}$ и $\mathrm{E}_{1}$ является сильно инвертированным, что обеспечивает создание интенсивного излучения при переходе частиц с уровня $\mathrm{E}_{2}$ на основной уровень. Вместе с этим и, а возбужденные электроны эрбия, которые расползается вдоль сердцевины ОВ, воздействует ОИ полезен ОС, вызывающей стимулированию эмиссию, что в свою очередь, создает дополнительные фотоны, с также оптической систем, создавая тем самом его усиление.

Основные параметры РЗМ Таблица 1

\begin{tabular}{|c|c|c|c|c|c|c|c|}
\hline \multirow[t]{2}{*}{ Элемент } & \multirow{2}{*}{$\begin{array}{l}\text { Плотност } \\
\text { ь } \\
\text { г/ } \mathrm{cM}^{3}\end{array}$} & \multicolumn{2}{|c|}{ Температура } & \multirow{2}{*}{$\begin{array}{l}\text { Тип } \\
\text { решетки }\end{array}$} & \multirow{2}{*}{$\begin{array}{l}\text { Расст. } \\
\text { между } \\
\text { соседи } \\
\text { атомами }\end{array}$} & \multirow{2}{*}{$\begin{array}{l}\text { Число } \\
\text { электронов } \quad \text { на } \\
\text { энер.ур }\end{array}$} & \multirow{2}{*}{$\begin{array}{l}\text { примечени } \\
\text { е }\end{array}$} \\
\hline & & $\begin{array}{l}\text { плавл } \\
\text {. }\end{array}$ & $\begin{array}{l}\text { кипени } \\
\text { я }\end{array}$ & & & & \\
\hline $\begin{array}{l}\text { Церий } \\
\text { Се }\end{array}$ & 6,8 & 797 & 3260 & - & & $2,8,20,18,8,2$ & \\
\hline $\begin{array}{c}\text { Празеоди } \\
\text { м } \\
\text { Pr }\end{array}$ & 6,7 & 935 & 3210 & - & & $2,8,21,18,8,2$ & \\
\hline $\begin{array}{c}\text { Неодим } \\
\mathrm{Nd}\end{array}$ & 7,0 & 1024 & 3130 & - & & $2,8,22,18,8,2$ & \\
\hline $\begin{array}{l}\text { Самарий } \\
\text { Sm }\end{array}$ & 7,54 & 1072 & 1750 & $\begin{array}{c}\text { Ромбо- } \\
\text { эдрическа } \\
\text { я }\end{array}$ & 3,59 & $2,8,24,18,8,2$ & \\
\hline $\begin{array}{c}\text { Гадолини } \\
\overline{\text { й }} \\
\mathrm{Gd} \\
\end{array}$ & 7,89 & 1312 & 3231 & $\begin{array}{c}\text { Гекса- } \\
\text { гональная }\end{array}$ & 3,58 & $2,8,25,18,8,2$ & \\
\hline $\begin{array}{l}\text { Тербий } \\
\text { Тb }\end{array}$ & 8,27 & 1364 & 3040 & $\begin{array}{c}\text { Гекса- } \\
\text { гональная }\end{array}$ & 3,52 & $2,8,27,18,8,2$ & \\
\hline $\begin{array}{c}\text { Диспрози } \\
\overline{\text { й }}\end{array}$ & 8,53 & 1407 & 2315 & $\begin{array}{c}\text { Гекса- } \\
\text { гональная }\end{array}$ & 3,51 & $2,8,28,18,8,2$ & \\
\hline
\end{tabular}

Physical, Chemical Science and Engineering 


\begin{tabular}{|c|c|c|c|c|c|c|c|}
\hline Dу & & & & & & & \\
\hline $\begin{array}{c}\text { Гольмий } \\
\text { Но }\end{array}$ & 8,70 & 14 & 2570 & ГПУ & & $2,8,29,18,8,2$ & \\
\hline $\begin{array}{c}\text { Эрбий } \\
\text { Ег }\end{array}$ & 9,04 & 1497 & 2519 & ГПУ & 3,47 & $2,8,30,18,8,2$ & \\
\hline $\begin{array}{c}\text { Тулий } \\
\text { Тт }\end{array}$ & & & & ТЦК & 3,88 & $2,8,32,18,8,2$ & \\
\hline $\begin{array}{c}\text { Иттербий } \\
\text { Үв }\end{array}$ & 6,97 & & & $2,8,31,18,8,2$ & \\
\hline
\end{tabular}

Типовых характеристики волоконно - оптические усилителей на легированном Еr волокне имеют усиление 0-50 дБ, выходной мощность $1 \div>400$ мВт показатель шума 3,5 - 12 дБ диапазоне длин волн 1520-1570 HM.

При анализе возможностей использования других РЗМ для создания оптических усилителей имеется ряд проблем. В таблице 4 проведены все имеющиеся РЗМ и их основные параметры.

Основные проблемы которые необходимо решить при дальнейших разработок волоконно-оптических усилителей (ВОУ) на основе легированных РЗМ оптических волокон.

1) Введение в оптический материал необходимой концентрации примеси Р3М,

2) Создания устройства для ввода эксперимента,

3) Выбор длины волы сигнала накачки.

При рассмотрены этих задач можно констатировать это первые результаты в июле 1960 год были представлены их стеклянном волокне с покрытом из неодима (Nd) при длине волн 1,06 или [3], позднее этом же котором был разработан первый лазер на стекле с присадкой первый эрбия [1], тоже это идея нашла применение для создания ВОУ для изготовления ОВ используемого ВОЛС. Были созданы целевая для создания ВОУ на 1,55 мнм - наиболее важном диапазоне для телекоммуникации, а также разработка ОИ только одной моды дано возможности в максимальной степень не только снизить потери, но и уменьшить искажения сигналов в ВС.

В 1999 году было [2] возможности и большой потенциал использования ВОУ нового поколения в современных магистральных Physical, Chemical Science and Engineering 
оптоволоконных материалов что дало толчок для исследований по разработка новых технологий по обработки ОУ для использования в оптических усилителей на основе присадок РЗМ. Из исследованных методов введение было легирующих присадок в ОВ были связаны с использованием легирования с помощью высоко - энергетичных ускорителей ионов (до неполных Мэ, что является нетехнологичным и дорогостоящим методом, но подобные исследования позволили найти ряд новая результатов по возможности легирования оптических материалов РЗМ). Из других методов можно упомянуть введение чисто химическими методами в процессе изготовления ОВ (например, химическим парофазным определением или испарением хлоридов РЗМ (4 5)). Однако, эти методы не могут обеспечить достаточно высокой концентрации легирования по глубже образцов, равномерного распределение внедрений примеси по объему образца и трудно потребление.

В настоящее время разрабатываются методы ионного легирования ОМ, используемых в волоконно-оптических усилителях. Суть этого метода заключается в обработке поверхности ОМ положительно заряженными ионами РЗМ с энергиями от неполных десятков до сотен КэВ и нанесения на поверхность ОМ слоя РЗМ с последующей термической диффузией. Ионное легирование ОМ позволяет в условиях высокого вакуума вводить примесь в приповерхностные и поверхностные слои обрабатываемые ОМ с высокой точностью и воспроизводимостью. 


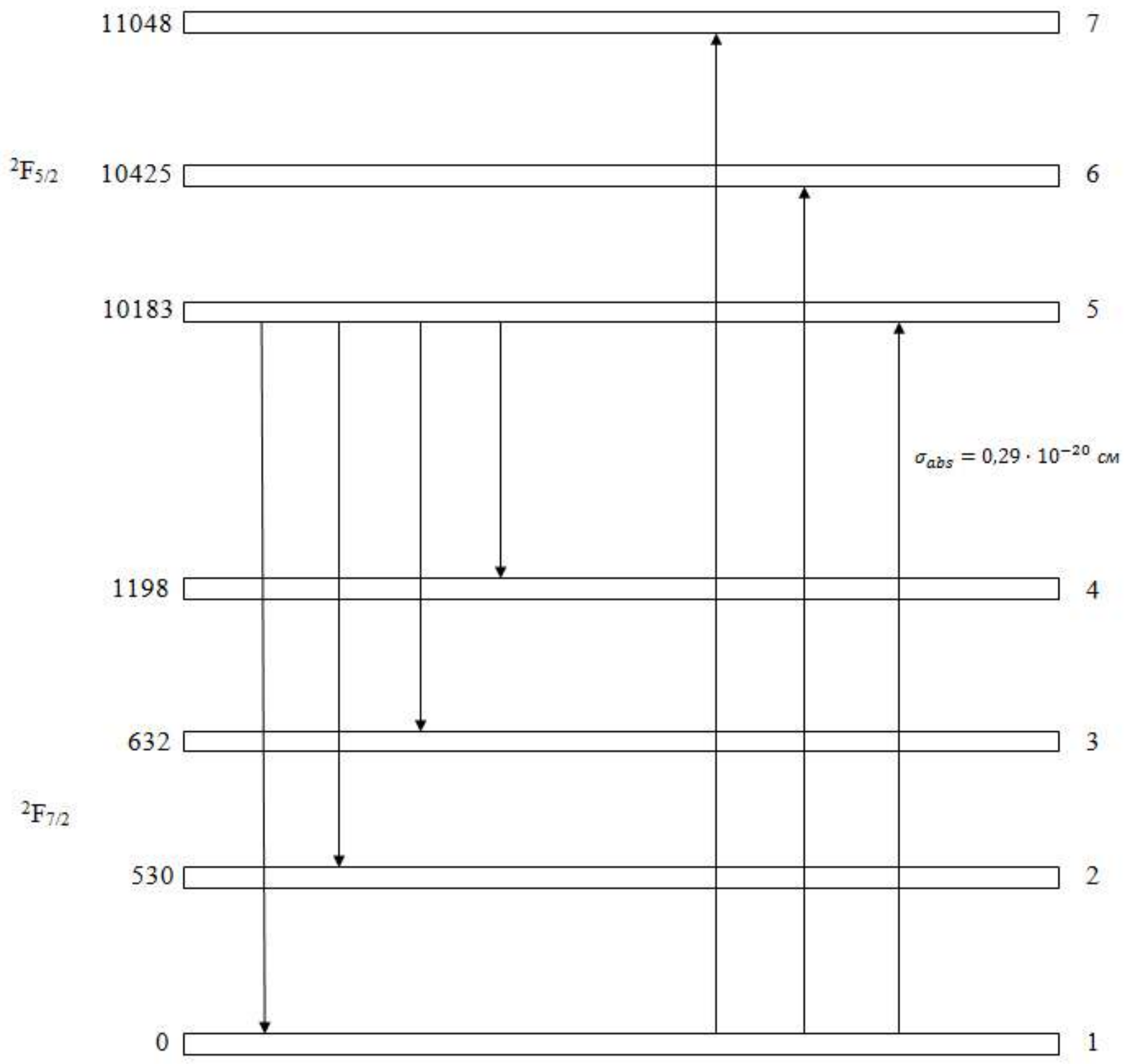

Рис. Уровневая диаграмма переходов трехвалентного иона эрбия.

В целом процесс ионного легирования состоит из следующие этапов: создание паров рабочего материала (например Er) порядка 1 Па, эти пары поступает в источник ионов, где ионизируются, экстракция ионов из области ионизации, формирование потока ионов путем его вытеснения с помощью_специальной ионно-электронной системы, сопряжения ионного потока от посторонних примесей ускорение ионов

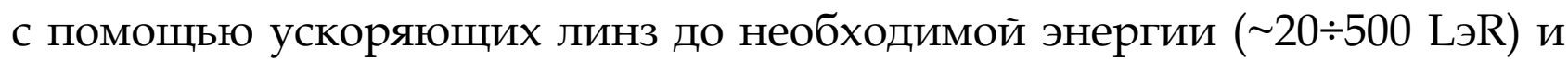


обработка поверхности ОМ потоком ионов_в течение заданного интервала времени.

Проведенная оценка глубины проникновения ионов РЗМ в приповерхностные слои ОМ [6] показала, что при энергиях ионов до 100КэВ максимальное проникновение составляет 140нм, а при энергиях до 300КэВ соответственно 380нм. Для получения достаточно высокой концентрации РЗМ (например Er) дозы облучения находятся в пределах $10^{15} \div 10^{17}$ и/см² . Распределение РЗМ в этом случае при этом максимум и его глубина концентрации зависят от энергии бомбардирующих ионов.

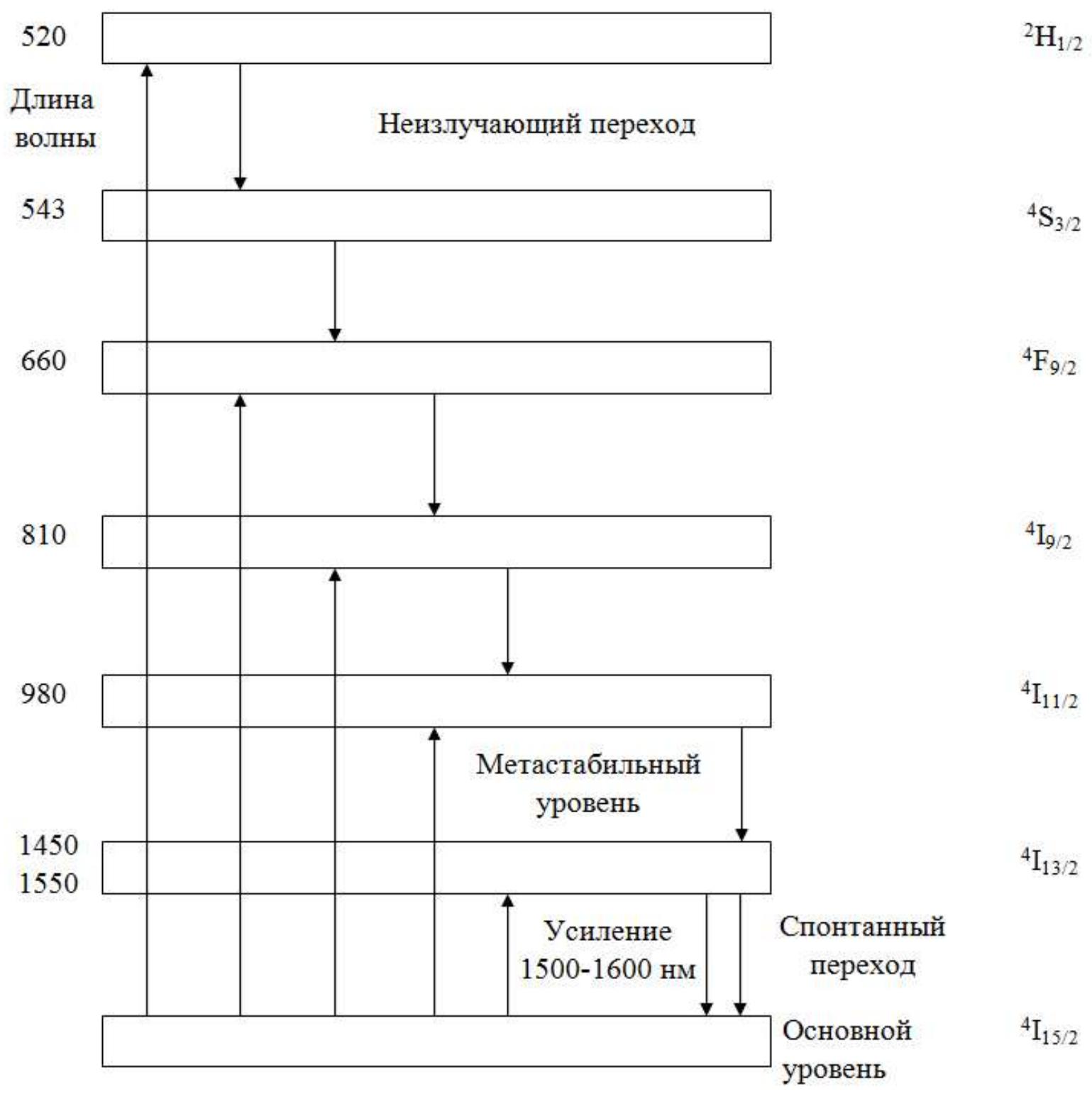


Рис. $\mathrm{Yb}^{3+}$ диограмма энергетического уровня в Fobyb (oxyboroapatite fiber $5 \% \mathrm{Yb}^{3+}$ )

Таким образом, метод ионно-плазменной имплантации введения легирующих примесей РЗМ является перспективным и эффективным.

В настоящее время эксперименты с ОМ с внедрением Er методом ионно-плазменной имплантации уже были использованы для создания на их основе оптических усилителей и предварительные испытание показали хорошие результаты [7]. Можно ожидать, что в скором времени подобные усилители будут широко использоваться в скоростных волоконно-оптических системах большей протяженности. 


\section{References / Литература}

1. Nakagawa K.. Nishi S.. Yoneda E. //J. Lightwawe Teclmol. 1991. V. 9. P. 198-207.

2. Randy G., Tingyc L. I. // Proc. IEEE. 1996. V. 84. P. 870-883.

3. Urquhart P. // Proc. IEEE. 1988. V. 6. P. 385-407.

4. Trivedi D. A., Strite T.. Gerlas van den Hoven // WDM solutions. 2000. № 4. P. 14-20.

5. Daniel C. McCarthy // Photonics Spectra. 2001. № 7. P. 88-98.

6. Yvonne Carts-Powell // WDM solutions. 2001. № 7. P. 9. 20.

7. Islam M., Nietubyc M. // WDM solutions. 2001. № 3. P. 53-62.

8. Hecht .T. // Laser Focus World. 2001. № 6. P. 135-140.

9. Ahmed M. H., Shalaby M., Misk F. M. // Pure Appl. Opt. 1998. V. 7. P. 659-666.

10. Savage N. // WDM solutions. 2000. № 4. P. 8.

11. Bains S. // WDM Solution. 2001. № 4. P. 9.

12. Jean-Laude, DWDM Fundamentals, Components, and Applications, Artech House, January 2002 y.

13. Clifforrd Headley, Goving Agrawal, Raman Amplification in Fiber Optical Communication Systems, academic press, December 2004 y. 